\title{
The Calcutta Rapid Transit System and the Park Street underground station
}

\author{
K. N. DASGUPTA, A. SENGUPTA \& T. ROY
}

\section{Mr J. T. Edwards. Freeman Fox \& Partners}

The Authors are to be congratulated on the lucid manner in which they have related how some of the problems which are inevitably encountered when large underground structures are built in poor ground in urban areas have been solved.

34. I understand the reasons as stated for designing Park Street Station as an experimental layout. However, the need for a subway under the tracks illustrates one of the disadvantages of the shallow, side platform layout. All passengers are involved, either on their outward or inward journey, in making a decision as to whether to use a less convenient entrance or to tolerate the additional upwards and downwards movement.

35. Regarding the decision not to use any sections of diaphragm walling in the permanent structure, I would like to know if there were not some sections where ground conditions would have permitted its use. A certain amount of leakage may be tolerated in the running tunnels and substantial savings can be made by incorporating the diaphragm walling, or contiguous piling, in the permanent structure. A suitable tolerance on the line of the wall will eliminate infringements of the structure gauge.

36. I would like to know more about the design and construction of the concrete track. From Figs 3 and 4 it appears to consist of an additional slab laid on the invert slab. There is a central open drain which will have to be connected to the tunnel drainage system. This drain may also impede the safe detraining of passengers unless (as may well be the intention) a separate walkway, at the expense of tunnel size, is provided alongside the track.

37. The choice of concrete track is a good one for many reasons. I do not understand why the turnouts are to be ballasted, when it is at junctions that the greatest difficulty in maintaining line and level is experienced. In Hong Kong all running lines and their junctions are on concrete, the only ballasted sections being in depots. The turnouts are expected to require the minimum maintenance, with none to line and level, whereas ballasted ones will be susceptible to disturbance by impact at the switches and crossings. How is a smooth transition between track on concrete slab and that on ballast assured?

Paper published: Proc. Instn Civ. Engrs, Part 1, 1979, 66, May, 261-275. 
38. Another point regarding tunnel design is the provision of the central row of columns. Although such an arrangement has been used in many systems, are any measures to be taken to protect the columns against damage from derailment? A dividing wall, rather than columns, would have additional advantage of making it easier to provide a controlled ventilation system, which may be an important factor in Calcutta and reduces the risk of spreading fire. Was a dividing wall considered? If it was rejected, was minimum cost a ruling factor?

\section{Mr Dasgupta, Mr Sengupta and Mr Roy}

The points made by Mr Edwards in $\$ 34$ are well taken. However, the considerations stated in $\$ 10$ prompted the project authorities to adopt the experimental layout.

40. The use of diaphragm walls as permanent box walls would have necessitated the provision of soldier piles with wooden lagging on top of the diaphragm walls in order to make the top slab rest directly on the diaphragm walls. The condition of the utilities, especially the sewers, in Calcutta does not permit the use of such an arrangement at most locations. However, there is an experimental stretch where the arrangement suggested by $\mathrm{Mr}$ Edwards has been tried. At this location there was an old brick sewer which had been leaking for some time and had formed mud pockets close to the soldier piles. The mud from these pockets leaked through the gaps in the lagging in the soldier piles and resulted in failure of the sewer.

41. Further, diaphragm wall work in a long stretch is bound to give rise to some defective joints between panels. Seepage through such joints could be quite serious. There is also the problem of effecting a proper joint between the bottom slab and the diaphragm wall.

42. In any case, the cost that would have been saved is only that of constructing the wall. It was considered by the project authorities that the economy that would have been effected was simply not commensurate with the risks involved. Perhaps it is on this account that this arrangement is not used in most countries for metro construction in poor soils.

43. The track proposed for most of the length in the Calcutta Metro is to be of the ballastless variety on a concrete bed laid in situ, known as second pour concrete. Tests are still going on on an experimental stretch of such track assembled on a suburban line near Calcutta. The following three kinds of track assembly are under test.

(a) M1A assembly consists of rails placed on rubber pads and bearing plates resting on the second pour concrete. Various features have been incorporated in this assembly to ensure resilience of the track as well as insulation for track circuiting purposes.

(b) M6 assembly consists of hardwood sleeper blocks fixed to the second pour concrete bed by steel studs homing into polythene inserts. The rails in this case are fixed to the sleeper blocks with elastic spikes.

(c) In $\mathrm{M} 7$ assembly the rails rest directly on the second pour concrete bed. Arrangements for track circuiting and resilience are also incorporated.

44. The drain shown in Figs 3 and 4 will be covered with a perforated cover so as not to impede safe detraining of passengers in the event of an emergency. No walkway is proposed to be provided alongside the track. Emergency evacuation is proposed to be effected through vestibules and end doors. 
45. The turn-outs in the metro track are to be of special design using 1 in 10 crossings and thick web alloy steel rails. These turn-outs have been designed for a speed of $40 \mathrm{~km} / \mathrm{h}$ over the turn-out track. Considerable wear and tear is expected in these assemblies. It was considered that adoption of ballasted track in such a location would not only keep down the wear and tear, but would also facilitate replacement and repairs to a great extent. This is the first time that this special assembly and that concrete track are being tried out by the Indian Railways. The evolution of the track design has to be through trial and error; a little conservatism in design is not, therefore, unwarranted. A turn-out on a concrete track has, however, been designed but not yet put to test. As for transition between track on concrete slab and that on ballast, a suitable run-off frame similar to the one normally used by the Indian Railways at the ends of girder bridges may be tried. In any case, the ballast in the ballastless track is contained from all sides, and is thus expected to behave quite differently from unconfined ballast on ground.

46. The gap between the dynamic profile of the coach and the columns is expected to provide sufficient guarantee against damage to the columns from derailment. It was considerations of ventilation which really decided in favour of columns rather than a dividing wall. Considering the hot and humid climate of Calcutta and the socio-economic picture, the optimum ventilation system should be designed to feed cooled air at stations only. If dividing walls had been provided, this would have resulted in the warmer tunnel air being driven into stations, and so would have precluded the use of this system of ventilation. Also a larger volume of air would have had to be handled. It was considered that in case of fire in one track the adjacent track could serve as an escape route, which would not have been possible if dividing walls had been provided. The space between the walls at locations is also proposed to be used for locating diverse machinery such as impedence bonds, relay boxes, fire hose stations etc., thus effecting economy by saving on the total width of the box. 